\title{
miR-639 promotes the proliferation and invasion of breast cancer cell in vitro
}

\author{
Lin Li, Xin-guang Qiu*, Peng-wei Lv and Fang Wang
}

\begin{abstract}
Breast cancer is characterised by an elevated capacity for tumour invasion and lymph node metastasis, but the cause remains to be determined. Recent studies suggest that microRNAs can regulate the evolution of malignant behaviours by regulating multiple target genes. In this study, we have first confirmed that miR-639 is up-regulated in metastatic breast cancer tissues and cell line with highly invasive capacity. Furthermore, we provided evidence to demonstrate that up-regulation of miR-639 contributes breast cancer invasion and metastasis. These data reveal a key role of miR-639 in breast cancer metastasis and support biological and clinical links between miR-639 and breast cancer.
\end{abstract}

Keywords: miR-639, Breast cancer, Invasion, Metastases

\section{Introduction}

Breast cancer-related deaths are caused by cancer metastases rather than the primary tumor. Different subtypes of breast cancer exhibit distinct metastases behaviors in terms of the temporal kinetics and anatomic sites. Estrogen receptor-positive $(E R+)$ breast cancer, predominantly recurs in bone after the diagnosis of the primary tumor [1]. The main mechanisms underlying these observations, however, remain to be elucidated.

MicroRNAs (miRNAs) are small, endogenous, noncoding RNAs which play important gene-regulatory roles in animals via sequence-specific interactions with the $3^{\prime}$ UTR of cognate mRNA targets, causing suppression of translation and mRNA decay [2]. It has been firmly established that miRNAs regulate many key cellular processes such as cell growth, differentiation and apoptosis [3,4]. About $50 \%$ of annotated human miRNAs are detected in regions of fragile sites, which are associated with cancer. Experiments have confirmed that miRNAs participate in the tumorigenesis progression of many types of cancers, including the breast cancer [5]. Although the number of verified human miRNAs is still expanding, the functions of only a few have been described. Subsets of miRNAs have been identified as potential diagnostic and prognostic

\footnotetext{
* Correspondence: xinguangqiu@126.com

Department of Breast Surgey, the First Affiliated Hospital of Zhengzhou University, No. 1, East Jian she Road, Zhengzhou 450052, Henan Province, China
}

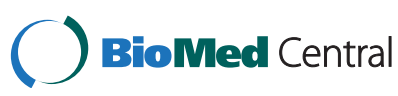

markers in malignant tumors [6-8]. MiR-639 has been reported to have disrupted expression in pathological states $[9,10]$. Similarly, miR-639 has been proven to be dysregulated in in serum of patients with bladder cancer. Therefore, the role of miR-639 in breast cancer caused us a great interest.

In this study, we examined the expression of miR-639 in breast cancer tissue samples and breast cancer cell lines. We found that miR-639 levels were up-regulated in metastatic breast cancer tissues and highly invasive cell lines. Furthermore, we have investigated the mechanism of miR-639 in breast cancer cell lines. These results show that exogenous overexpression of miR-639 promotes the invasion and migration of breast cancer cells in vitro.

\section{Materials and methods \\ Cell culture}

MCF-7 cancer cells are breast cancer derived and display an epithelial phenotype and low invasive capacity. MDAMB-231 (MD231) cancer cells are also breast cancer derived but these cells have a mesenchymal phenotype and high invasive capacity. Both these breast cancer cell lines were obtained from the American Type Culture Collection (ATCC). These cell lines were cultured in DMEM supplemented with 10\% heat-inactivated FBS (GIBCO BRL, NY, USA), penicillin (100 units/ml) and streptomycin $(100 \mu \mathrm{g} / \mathrm{ml})$ at $37^{\circ} \mathrm{C}$ in a humidified $5 \% \mathrm{CO}_{2}$ atmosphere. 


\section{Tissue samples and reagents}

All samples were obtained by surgery and quickly frozen in liquid nitrogen and stored at $-80^{\circ} \mathrm{C}$. Informed consent was obtained in advance for all patients selected in this study. In parallel, a separate cohort of 84 patients was assembled from a large pool of patients in the database based on histological diagnosis of breast cancer between 2001 and 2005. We retrospectively reviewed the medical records of patients. Total RNAs were extracted from paraffin blocks using the high pure miRNA isolation kit according to the manufacturer's protocol (Roche, Switzerland) before further analysis.

Both the miR-639 inhibitor and its mimics were purchased from GenePharma (Shanghai, China). The high pure miRNA isolation kit was purchased from Roche (Basel, Switzerland). The miRcute miRNA qPCR detection kit and miRcute miRNA qPCR detection kit were purchased from TIANGEN BIOTECH (Beijing, China).

\section{Real-time PCR analysis}

Real-time PCR reactions were performed using an ABI 7500 real-time PCR system (Applied Biosystems, CA). Reverse transcription of the extracted miRNA was performed with miRNA-specific primers using the miRcute miRNA first-strand cDNA synthesis kit, and real-time PCR of miRNAs was performed using the miRcute miRNA qPCR detection kit according to the manufacturer's protocol (TIANGEN BIOTECH, China), the primer is provided by the miRcute miRNA qPCR detection kit.

\section{Invasion assays and wound-healing experiment}

In vitro invasion assays, a total of $4 \times 10^{4}$ cells in $200 \mu \mathrm{l}$ serum-free DMEM medium were plated onto BD BioCoat ${ }^{\text {tm }}$ Matrige $^{\mathrm{Tm}}$ Invasion Chambers $(8 \mu \mathrm{m}$ pore size; BD Biosciences), and the lower chamber was immediately filled with $500 \mu \mathrm{l}$ of DMEM medium with 10\% FBS as a chemoattractant. After $24 \mathrm{hrs}$ of incubation in a humidified atmosphere containing $5 \% \mathrm{CO}_{2}$ at $37^{\circ} \mathrm{C}$, the membranes were then fixed with methanol and stained by $0.2 \%$ crystal violet. For wound-healing experiments, cells were plated in 6-well plates, transfected as indicated, and cultured to confluency. Cells were serum-starved and scraped with a P200 tip (time 0), and pictures (5 fields) were taken at the $24 \mathrm{~h}$ time points.

\section{Informed consent and ethical approval}

This study was approved by Institutional Ethic Committee Office of the First Affiliated Hospital of Zhengzhou University. Written informed consent was obtained from the patient for the publication of this article and accompanying images.

\section{Statistical analysis}

The categorical variables were compared among the groups using the $X$-squared test. The continuous variables were analyzed using the two-tailed Student's $t$-test. A $P$ value of $<0.05$ was considered statistically significant.

\section{Results}

The association of miR-639 expression with metastatic rates in patients with breast cancer

We first measured mature miR-639 levels in a group of tissue specimens from breast cancer patients. In the 82 metastatic breast cancer tissues, the expression level of miR-639 was $2.11 \pm 0.31$, whereas its expression level in the 76 tissues with non-metastatic breast cancer tissues was $1.19 \pm 0.14(P=0.024$; Figure $1 \mathrm{~A})$. These results showed that miR-639 expression levels in primary metastatic breast cancer tissues samples were significantly higher than those non-metastatic breast cancer tissues. The correlations between miR-639 expression levels and clinical pathological characteristics are summarised in Table 1. Statistically significant reverse associations between miR-639 expression levels and metastatic rates were observed. In the 74 breast cancer tissues with severe histological signs, the expression level of $m i R-639$ was $1.73 \pm 0.17$, which was also significantly higher than the expression level of $1.57 \pm 0.23$ in 77 tissues with non-histological signs $(P=0.038$; Table 1$)$.

We next analyzed mature miR-639 levels in the collection of breast cancer patients with clinical characteristics. Patients were divided into two groups with high or low
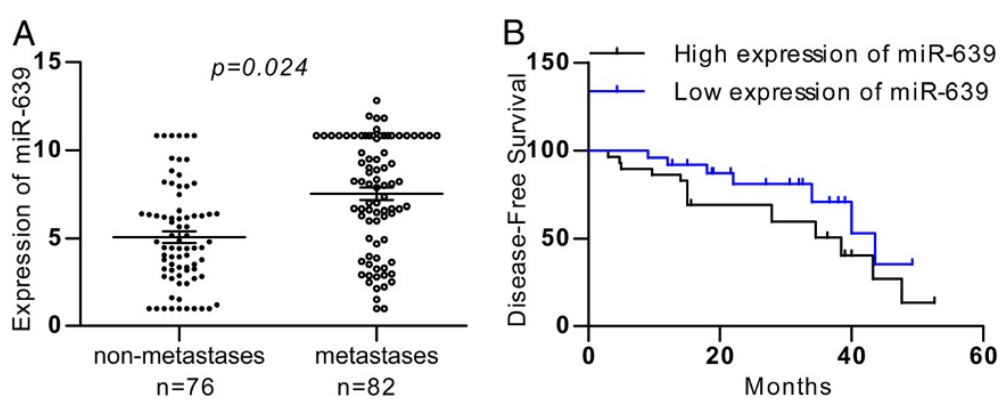

Figure 1 Clinical association of miR-639 with metastases in breast cancer patients. (A) Mature miR-639 levels were measured in breast cancer samples by real-time PCR. (B) Kaplan-Meier graph representing the probability of disease-free survival in breast cancer patients from the "Milan-INT" dataset stratified. The log-rank test $P$ value reflects the significance of the association between low miR-639 level and disease-free survival. 
Table 1 Associtions between miR-639 and clinical parameters $(n=158)$

\begin{tabular}{|c|c|c|c|c|}
\hline \multirow[t]{2}{*}{ Characteristic } & \multicolumn{2}{|c|}{ No. of patients } & \multirow{2}{*}{$\begin{array}{c}m i R-639 \Delta C t^{\mathrm{a}} \\
\text { Mean } \pm \mathrm{SD}\end{array}$} & \multirow[t]{2}{*}{$P$} \\
\hline & No. & $\%$ & & \\
\hline \multicolumn{5}{|l|}{ Age, years } \\
\hline$\geq 60$ & 69 & 43.7 & $1.71 \pm 0.17$ & \multirow[t]{2}{*}{0.664} \\
\hline$<60$ & 89 & 56.3 & $1.64 \pm 0.21$ & \\
\hline \multicolumn{5}{|c|}{ Pathologe grade } \\
\hline 1 & 56 & 35.4 & $1.69 \pm 0.21$ & \\
\hline$\|$ & 49 & 31.0 & $1.86 \pm 0.14$ & \multirow[t]{2}{*}{0.089} \\
\hline III & 53 & 33.5 & $1.98 \pm 0.15$ & \\
\hline \multicolumn{5}{|l|}{ T stage } \\
\hline $\mathrm{T} 1$ & 57 & 36.1 & $1.54 \pm 0.27$ & \multirow[t]{3}{*}{0.471} \\
\hline T2 & 50 & 31.6 & $1.65 \pm 0.24$ & \\
\hline T3 & 51 & 32.3 & $1.33 \pm 0.17$ & \\
\hline \multicolumn{5}{|l|}{ M stage } \\
\hline MO & 76 & 48.1 & $1.19 \pm 0.14$ & \multirow[t]{2}{*}{0.024} \\
\hline M1 & 82 & 51.9 & $2.11 \pm 0.31$ & \\
\hline \multicolumn{5}{|c|}{$\begin{array}{l}\text { Histologic signs of severity } \\
\text { (vascular emboli, perineural } \\
\text { invasion, diffuse infiltration) }\end{array}$} \\
\hline None & 77 & 48.7 & $1.57 \pm 0.23$ & \multirow[t]{3}{*}{0.038} \\
\hline Presence & 74 & 46.8 & $1.73 \pm 0.17$ & \\
\hline Missing & 7 & 4.4 & & \\
\hline \multicolumn{5}{|c|}{ Smoking history } \\
\hline Nonsmoker & 111 & 70.3 & $1.37 \pm 0.23$ & \multirow[t]{3}{*}{0.625} \\
\hline Smoker & 39 & 24.7 & $1.47 \pm 0.21$ & \\
\hline Missing & 8 & 5.1 & & \\
\hline \multicolumn{5}{|l|}{ Alcohol history } \\
\hline Nondrinker & 107 & 67.7 & $1.35 \pm 0.29$ & \multirow[t]{3}{*}{0.225} \\
\hline Drinker & 42 & 26.6 & $1.27 \pm 0.36$ & \\
\hline Missing & 9 & 5.7 & & \\
\hline
\end{tabular}

Abbreviations: $S D$ standard deviation, $T$ tumor stage, $N$ lymphnode stage. ${ }^{\mathrm{a}} \Delta \mathrm{Ct}$ indicates the difference in the cycle number at which a sample's fluorescent signal passes a given threshold above baseline (Ct) derived from a specific gene compared with that of $U 6$ in tumor tissues.

levels of miR-639. Remarkably, when tested using the Kaplan-Meier survival analysis, the miR-639 "low expression" group displayed a significantly longer disease-free survival rates when compared to the "high expression" group (Figure 1B). These data suggest a possible link between miR-639 expression and breast cancer progression.

\section{miR-639 promotes cell proliferation}

MCF-7 cancer cells are breast cancer derived and display an epithelial phenotype and low invasive capacity. MD231 cancer cells are also breast cancer derived but these cells have a mesenchymal phenotype and high invasive capacity and contained a relatively high level of miR-639 (Figure 2A).
First, we assessed the growth of miR-639-transfected and miR-NC-transfected MCF-7 cells after transient transfection. As shown in Figure 2B, miR-639 was able to increase the proliferation of miR-639-transfected cells compared with miR-NC-transfected cells significantly at day 3 and 5 $(\mathrm{P}<0.05$, Student's $\mathrm{t}$-test). We further tested if endogenous expression of miR-639 was required for breast cancer cell invasion in the higher metastatic cancer cell line MD231. For this purpose, we silenced miR-639 and this treatment led to an approximately 2 -fold decline in growth properties (Figure 2C).

\section{Ectopic expression of miR-639 promotes cancer metastasis}

In light of the preceding data, we aimed to determine more directly if miR-639 plays a causal role in the aggressive traits of breast cancer cells. MCF-7 cancer cells display an epithelial phenotype and low invasive capacity and MD231 cancer cells have a mesenchymal phenotype and high invasive capacity. We used these cell lines to investigate how gain or loss of function of miR-639 impacted cell migration and invasion, which are hallmarks of metastatic capacity. The MD231 cells displayed high migration capacities and contained a relatively high level of $m i R-639$ (Figure 2A). In the transwell assays shown in Figure 3B, down regulation of miR-639 in MD231 cells decreased invasive abilities 3 -fold compared to the same cells expressing miR-NC. We further tested if endogenous expression of miR-639 was required for cell invasion in the lower metastatic cancer cell line MCF-7. For this purpose, we upregulated miR-639 and this treatment led to an approximately 2-fold augmentation in invasive properties (Figure 3A). Furthermore, the pro-migration effects of miR-639 were observed in wound-healing assays in MCF-7 and MD231 cells (Figure 3C and D).

\section{Discussion}

Although a global reduction of miRNA abundance appears to be a general trait of human cancers, playing a causal role in the metastatic phenotype [11-13], several miRNAs are up-regulated in tumors [14], Recently, miRNAs have been shown to be related to tumor metastasis [15], providing a new perspective on the metastatic process. Nonetheless, The role of miRNAs in breast cancer has been widely investigated. Here, we will focus on miRNA-639 promotes breast cancer metastasis.

In this study, we described for the first time the miR639 is markly upregulated in metastatic breast cancer in large samples. We also found that miR-639 is closely related to the cancer metastasis and miR-639 "high expression" group displayed a significantly poorer disease-free survival rates. We have proven that the down-regulation of miR-639 is crucial in breast cancer metastasis and demonstrated that miR-639 acts as a putative oncogene. MD231 cells, which stably express miR-639 ectopically, 


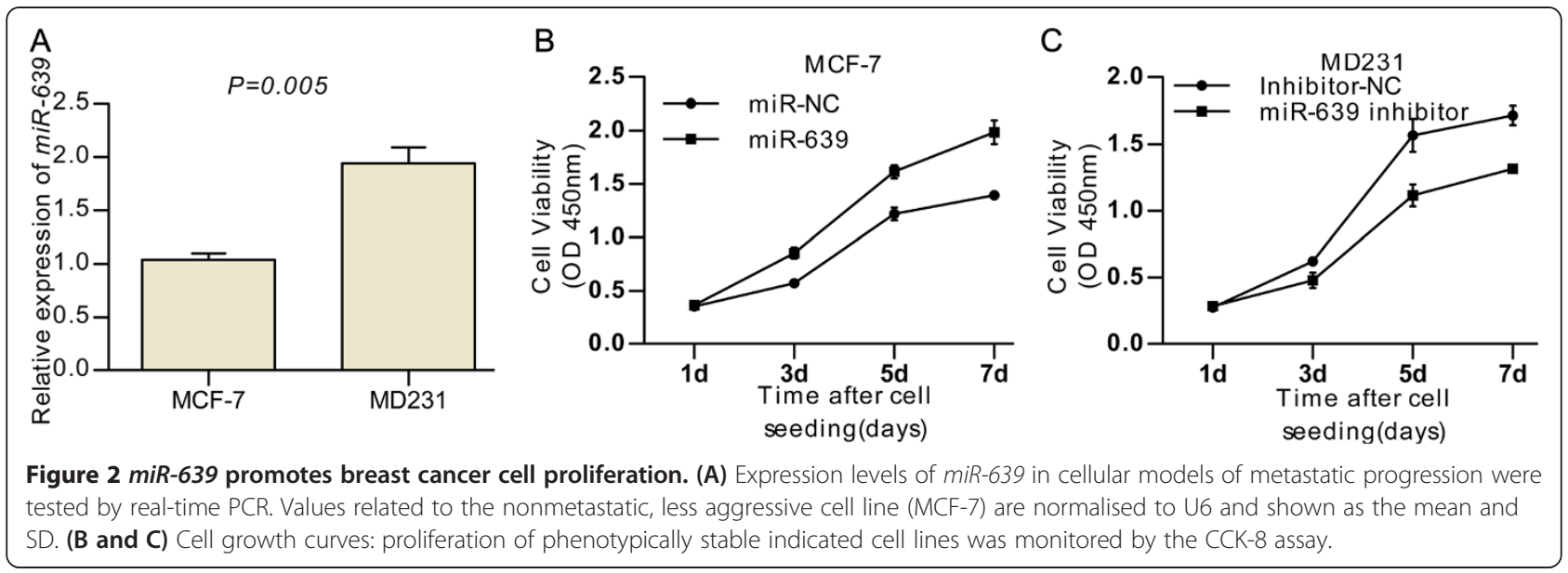

were transiently transfected with the miR-639 inhibitor, and MCF-7 cells were transfected with miR-639 mimics. This could be in line with the internal environment of the cells.

The genetic and epigenetic silencing of tumor suppressor genes is considered a vital molecular event in the development and progression of breast cancer [16]. This study first proves that miR-639 is up-regulated in metastatic breast cancer. Aberrant patterns of miRNA expression are implicated in human diseases including breast cancer. Recent studies have identified miRNAs regulated by estrogens in human breast cancer cells,
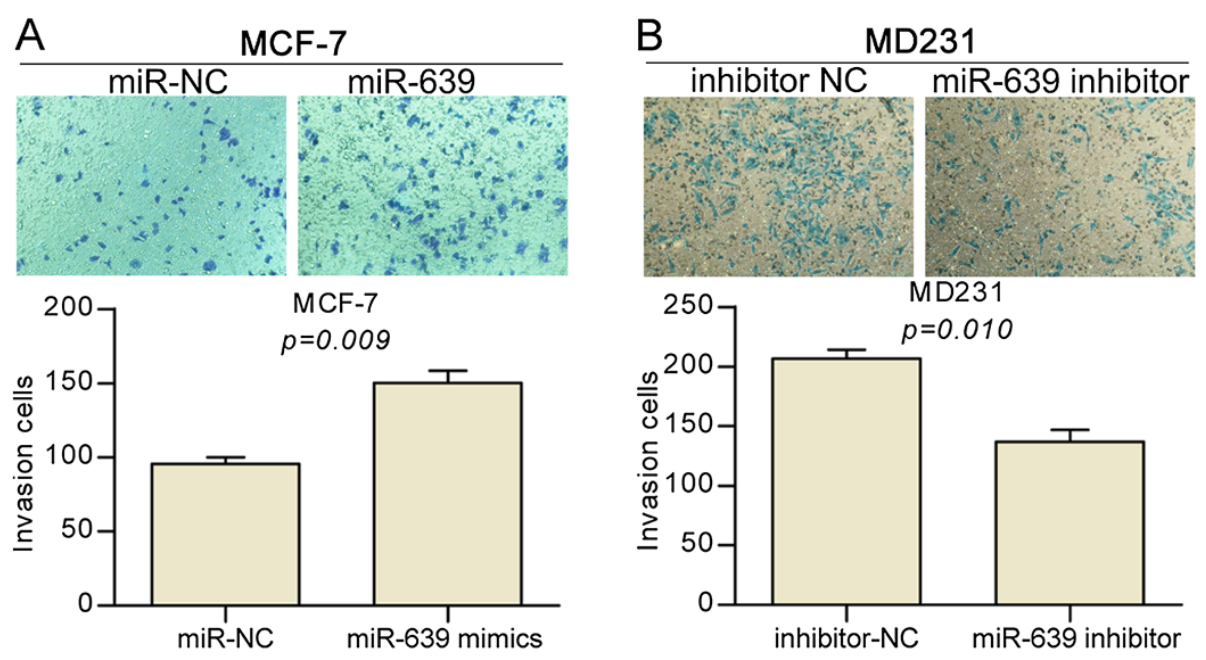

C
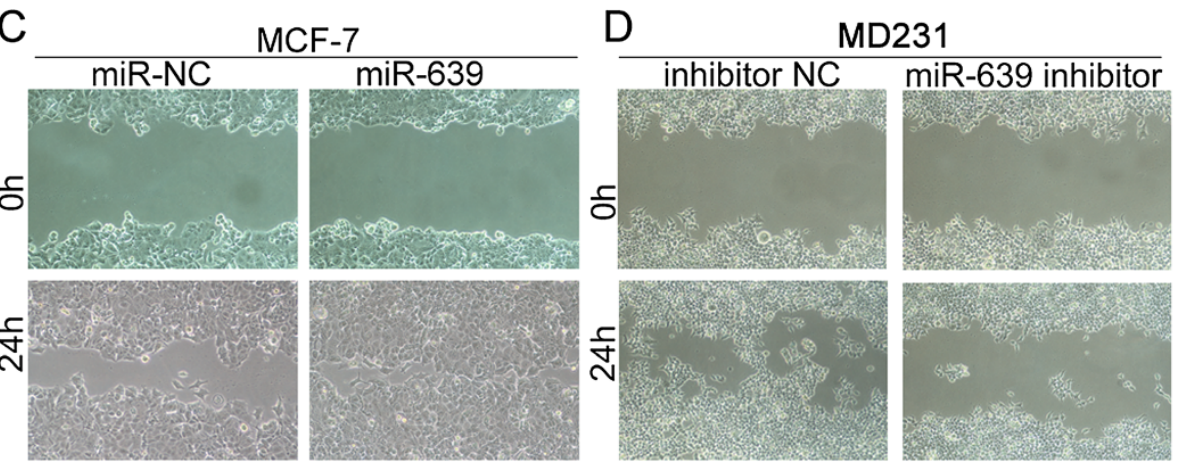

Figure 3 miR-639 promotes cell invasion and migration. (A and B) Representative pictures of cells migrated through the filter, stained with crystal violet, and taken at the same magnification and absolute quantifications as cells that had invaded through the transwell. (C and D) Wound-healing assay showing that gain of miR-639 promotes cell migration and loss of miR-639 supresses cell migration. 
human endometrial stromal and myometrial smooth muscle cells, rat mammary gland, and mouse uterus. The decline of estradiol levels in postmenopausal women has been implicated in various age-associated disorders [17]. The role of estrogen- regulated miR-639 expression has yet to be explored. As miRNAs function mainly through the inhibition of target genes and $\mathrm{Wu}$ et al. [18] showed p21Cip1/Waf1 expression was reduced by miR-639. This result may preliminary explain the mechanism of miR-639.

\section{Conclusion}

In conclusion, our results have proven that miR-639 plays a causal role in the metastases of breast cancer. These findings have implications for understanding the mechanism of breast cancer metastasis, and miR-639 may be a valuable maker and target for prevention or adjuvant therapy in breast cancer patients.

\section{Competing interests}

The authors declare no competing financial interests.

\section{Authors' contribution}

Guarantor of integrity of the entire study: XQ, LL. Study concepts and design: LL. Literature research: PL. Cancer cell and molecular studies: LL and FW. Experimental studies/data analysis: LL and PL. Statistical analysis and manuscript preparation: LL. Manuscript editing: XQ. All authors read and approved the final manuscript.

Received: 22 February 2014 Accepted: 1 May 2014

Published: 10 May 2014

\section{References}

1. Zhang XH, Giuliano M, Trivedi MV, Schiff R, Osborne CK: Metastasis dormancy in estrogen receptor-positive breast cancer. Clin Cancer Res 2013, 19(23):6389-6397.

2. Bartel DP: MicroRNAs: target recognition and regulatory functions. Cell 2009, 136(2):215-233.

3. Schickel R, Boyerinas B, Park SM, Peter ME: MicroRNAs: key players in the immune system, differentiation, tumorigenesis and cell death. Oncogene 2008, 27(45):5959-5974.

4. Zhang J, Guo H, Qian G, Ge S, Ji H, Hu X, Chen W: MiR-145, a new regulator of the DNA fragmentation factor-45 (DFF45)-mediated apoptotic network. Mol Cancer 2010, 9:211.

5. Ventura A, Jacks T: MicroRNAs and cancer: short RNAs go a long way. Cell 2009, 136(4):586-591.

6. Kent OA, Mendell JT: A small piece in the cancer puzzle: microRNAs as tumor suppressors and oncogenes. Oncogene 2006, 25(46):6188-6196.

7. Calin GA, Croce CM: MicroRNA signatures in human cancers. Nat Rev Cancer 2006, 6(11):857-866.

8. Hou J, Lin L, Zhou W, Wang Z, Ding G, Dong Q, Qin L, Wu X, Zheng Y, Yang Y, Tian W, Zhang Q, Wang C, Zhang Q, Zhuang SM, Zheng L, Liang A, Tao W, Cao $X$ : Identification of miRNomes in human liver and hepatocellular carcinoma reveals miR-199a/b-3p as therapeutic target for hepatocellular carcinoma. Cancer Cell 2011, 19(2):232-243.

9. Ragusa M, Caltabiano R, Russo A, Puzzo L, Avitabile T, Longo A, Toro MD, Di Pietro C, Purrello M, Reibaldi M: MicroRNAs in vitreus humor from patients with ocular diseases. Mol Vis 2013, 19:430-440.

10. Scheffer AR, Holdenrieder S, Kristiansen G, von Ruecker A, Muller SC, Ellinger J: Circulating microRNAs in serum: novel biomarkers for patients with bladder cancer? World J Urol 2012, 32(2):353-358.

11. Kumar MS, Lu J, Mercer KL, Golub TR, Jacks T: Impaired microRNA processing enhances cellular transformation and tumorigenesis. Nat Genet 2007, 39(5):673-677.

12. Lu J, Getz G, Miska EA, Alvarez-Saavedra E, Lamb J, Peck D, Sweet-Cordero A, Ebert BL, Mak RH, Ferrando AA, Downing JR, Jacks T, Horvitz HR, Golub
TR: MicroRNA expression profiles classify human cancers. Nature 2005, 435(7043):834-838.

13. Ozen M, Creighton CJ, Ozdemir M, Ittmann M: Widespread deregulation of microRNA expression in human prostate cancer. Oncogene 2008, 27(12):1788-1793.

14. Volinia S, Calin GA, Liu CG, Ambs S, Cimmino A, Petrocca F, Visone R, Iorio M, Roldo C, Ferracin M, Prueitt RL, Yanaihara N, Lanza G, Scarpa A, Vecchione A, Negrini M, Harris CC, Croce CM: A microRNA expression signature of human solid tumors defines cancer gene targets. Proc Natl Acad Sci U S A 2006, 103(7):2257-2261.

15. Sun Q, Zhang J, Cao W, Wang X, Xu Q, Yan M, Wu X, Chen W: Dysregulated miR-363 affects head and neck cancer invasion and metastasis by targeting podoplanin. Int J Biochem Cell Biol 2013, 45(3):513-520.

16. O'Regan EM, Toner ME, Finn SP, Fan CY, Ring M, Hagmar B, Timon C, Smyth P, Cahill S, Flavin R, Sheils OM, O'Leary JJ: p16(INK4A) genetic and epigenetic profiles differ in relation to age and site in head and neck squamous cell carcinomas. Hum Pathol 2008, 39(3):452-458.

17. Klinge CM: Estrogen regulation of MicroRNA expression. Curr Genomics 2009, 10(3):169-183.

18. Wu S, Huang S, Ding J, Zhao Y, Liang L, Liu T, Zhan R, He X: Multiple microRNAs modulate $\mathrm{p} 21 \mathrm{Cip} 1 /$ Waf1 expression by directly targeting its 3' untranslated region. Oncogene 2010, 29(15):2302-2308.

doi:10.1186/1475-2867-14-39

Cite this article as: Li et al: miR-639 promotes the proliferation and invasion of breast cancer cell in vitro. Cancer Cell International 2014 14:39.

\section{Submit your next manuscript to BioMed Central and take full advantage of:}

- Convenient online submission

- Thorough peer review

- No space constraints or color figure charges

- Immediate publication on acceptance

- Inclusion in PubMed, CAS, Scopus and Google Scholar

- Research which is freely available for redistribution 